\title{
MICROBES AS A TOOL TO DEFEND AGAINST ANTIBIOTIC RESISTANCE IN FOOD ANIMAL PRODUCTION
}

\author{
A. K. BHUNIA \\ Molecular Food Microbiology Laboratory \\ Department of Food Science \\ Department of Comparative Pathobiology \\ Purdue Institute of Inflammation Immunology and Infectious Diseases \\ Purdue University, West Lafayette, Indiana 47907, USA
}

\begin{abstract}
The antibiotic-resistant microbial community collectively referred to as antibiotic resistome is on the rise and largely attributed to indiscriminate use or misuse of antibiotics in food animal production, human medicine and in agriculture. Scientists are constantly looking for an answer to provide an effective and safe alternative to overcome the growing problem of antibiotic resistance. The best practice would be to reduce antibiotics use; however, it may not be adequate. Antimicrobials are necessary for food animal production, and treatment of diseases; therefore, alternative strategies must be employed. Plant or animal-derived antimicrobials, organic acids, prebiotics, immunostimulants, and new generation eco-friendly antibiotics have been proposed. Are they effective and credible to lessen our global antibiotic resistance crisis? In recent years, however, the use of microbes as a tool to defend against antibiotic resistome is gathering momentum. These microbes include bacteriophages, undefined or defined mixed microbial cultures, probiotic bacteria, and bioengineered microbes which may be able to reduce our dependence on antibiotics in food animal production and alleviate antibiotic resistance crisis.
\end{abstract}

Key words: Antibiotic resistance, Bacteriophages, Bioengineered, Microbiota, Probiotic

Evolution, adaptation and natural selection have shaped all living creatures, small or large on this planet. In all living entities, exposure to life-threatening conditions can trigger a coping mechanism. Microscopic organisms are also frequently being exposed to an array of antimicrobials including ultraviolet light, acids, alkali, chemical sanitizers, antimicrobial peptides, and antibiotics. Repeated exposure works as a selective pressure, which prompts microorganisms to undergo genetic mutation, or up-regulation or down-regulation of certain genes to develop a robust defense against a threat. Another interesting evolutionary aspect is that antibiotics disrupt microbial ecosystem thus enabling persistence of resistant population. Therefore, all microbes, irrespective of being primary pathogens, opportunistic pathogens or commensals have an equal chance of being exposed to the same antimicrobials when applied to food animals for growth promotion or therapeutic application. Therefore, they can contribute to the expansion of antibiotic resistome in the 
environment, animals, and humans. It has been suggested that antibiotic resistance for animal-specific pathogens may be a concern for veterinary medicine but may not be a major concern for human medicine. However, any veterinary drugs that are responsible for the induction of antimicrobial resistance (AMR) in zoonotic pathogens and commensals can have a direct impact on human health (Toutain et al., 2016).

Since the discovery of penicillin in 1928 by Alexander Fleming and its introduction as therapeutics in the 1940s, our confidence in combating disease-causing microorganisms grew exponentially without ever discerning of its long-term consequences. Now it has been well recognized by the scientific community that extensive and indiscriminate use of antibiotics in food animals, aquaculture and poultry for human food production and as therapeutics for treatment of human and animal diseases have fueled the crisis of antibiotic resistance (Neu, 1992; Davies and Davies, 2010; Beceiro et al., 2013; Rodriguez-Rojas et al., 2013; Van Boeckel et al., 2015; Pérez-Rodríguez and Mercanoglu, 2019). The most important factors attributed to the onset of AMR is when antibiotics are used at a sub-inhibitory or sublethal dosage and such nonlethal exposure may cause evolution and selection of antibiotic-resistant bacteria (Gullberg et al., 2011; Andersson and Hughes, 2014; Zhu et al., 2018) including the emergence of multidrug-resistant (MDR) bacterial pathogens, such as extended-spectrum $\beta$ lactamase (ESBL) producing Gram-negative bacteria (Carlet et al., 2012; Blair et al., 2014). However, discovering antibiotic resistance genes from ancient soil samples certainly, challenge our perception of the modern AMR problem. Metagenomics analysis of ancient soil samples such as 40,000-year-old permafrost suggests the presence of genes encoding resistance to $\beta$-lactam, tetracycline and glycopeptide antibiotics (D'Costa et al., 2011).

Nevertheless, antibiotic resistance is now widespread among different bacterial pathogens and even to different classes of antibiotics that target various cellular components, i.e., cell wall, protein, DNA, RNA, folic acid and mycolic acid synthesis. It has been estimated that about $80 \%$ of all antibiotics sold in the United States have been used in food animals as a growth promoter or to treat an animal infection (Marshall and Levy, 2011). Antibiotic resistance has been considered a global public health crisis and it has been predicted to cause 10 million deaths per year by 2050 (O'Neill, 2014). Though these numbers have been argued to be an overestimate (de Kraker et al., 2016), the scientists agree that AMR problem is real and the situation would be grave unless remedial actions are taken (Toutain et al., 2016; Ferri et al.,2017; Pérez-Rodríguez and Mercanoglu 2019). In the U.S., antibiotic-resistant bacteria have been responsible for more than 2 million infections and 23,000 deaths annually (CDC, 2018) while in the European Union (EU), it is about 672,000 infections and 33,000 deaths per year (Cassini et al., 2019).

The scientific community is constantly looking for an answer to provide an effective and safe alternative to antibiotics to overcome the growing problem of antibiotic resistance. In order to develop strategies to combat antibiotic resistance one has to recognize how wide-spread this problem is and the potential sources of antibiotic resistance and the 
contributing factors. It is nearly impossible to completely eliminate antibiotic resistance in microbes, but the clinical or animal husbandry practices that can reduce further development of acquired resistance to antibiotics should be explored. One caveat, any credible solution to reduce antibiotic resistance in bacteria should be able to withstand the resistant mechanisms used by bacteria in the first place. Therefore, in recent years, the use of microbes such as bacteriophages, undefined or defined mixed microbial cultures, probiotic bacteria, and bioengineered microbes as a tool to defend against antibiotic resistome has been proposed (Kutateladze and Adamia, 2010; Amalaradjou and Bhunia, 2013; Pamer, 2016; Ryan and Bhunia, 2017; Wong and Santiago, 2017; Relman and Lipsitch, 2018) and this review will examine benefits and limitations of such approaches.

\section{Sources of antibiotic resistance}

Antibiotics as a growth promoter in animal husbandry: In modern food animal production practices, animals are housed in large groups with high animal densities thus there is a chance for rapid disease spread. Antibiotics as therapeutic or prophylactics are of great importance in such farming practices (Wegener, 2003). Antibiotics are used in feed or water for the treatment of sick animals as therapeutic. Likewise, prophylactic use of antibiotics in feed is a common practice to prevent diseases caused by infectious agents (Wegener, 2003). In addition, antibiotics are also used for growth promotion and such antibiotic use is speculated to grow (Van Boeckel et al., 2015). Antibiotic concentration is much higher for therapeutic and prophylactic applications while growthpromoting antibiotics are used at a dosage that is sub-therapeutic, which may be considered sub-minimum inhibitory concentration (MIC) and is a major contributor for the development of human resistome. For example, increased incidence of vancomycin (glycopeptide antibiotic) resistant enterococci (VRE) in food animals and subsequently in humans was attributed to the use of avoparcin, a glycopeptide antibiotic in animal feed as a growth promoter (Bager et al., 1997). The ban of avoparcin in animal feed in the EU has markedly reduced human VRE resistome (Wegener, 2003). Likewise, there is a concerted effort to prohibit the use of human therapeutic antibiotics such as penicillin, tetracycline, etc as growth promoters (Mathew et al., 2007; Cheng et al., 2014). Since 2017, the US Food and Drug Administration (FDA) has banned the use of "medically important antibiotics" as antibiotic growth promoters in food animals (Brüssow, 2017). To further alleviate concerns for the contribution of veterinary drugs for the onset of human resistome, there is an impetus for the development of new eco-friendly drugs that would have a minimal ecological impact on animal commensal and the environmental microbiome (Toutain et al., 2016).

Antibiotics as a therapeutic drug: Therapeutic application of antimicrobials in the treatment of specific pathogens in veterinary medicine has not been considered a major concern for the onset of antibiotic resistome for human health (Toutain et al., 2016). However, the effect of veterinary antibiotics on the zoonotic pathogens and the commensal resident bacteria in the host can have serious consequences which can contribute to the abundance of antibiotic resistome in humans and in the environment. Increased incidence of antibiotic-resistant 
foodborne Salmonella, Campylobacter and $E$. coli have been attributed to the use of antibiotics in food animals (Toutain et al., 2016). Furthermore, the indiscriminate prescription of antibiotics in both human and veterinary medicine practices without definitive identification of a causative infectious agent can exacerbate the AMR problem. Therefore, the stewardship for antibiotic use in human or veterinary medicine practices should be greatly emphasized.

In addition, the application of sub-inhibitory or sublethal antibiotic dosage has been attributed to be a major contributing factor for the onset of antibiotic resistance. Sublethal exposure can occur not only from improper use of antibiotics during therapeutic application but also from patients (human/ animal) fecal waste and also pharmaceutical industry waste. Both can contribute to the environmental sub-inhibitory antibiotic pool to serve as a major selection pressure for the development of antibiotic resistome (Bengtsson-Palme and Larsson, 2016).

To further alleviate concerns for the contribution of veterinary drugs for the onset of human resistome, the FDA has approved several veterinary antibiotics, referred to as Veterinary Feed Directive (VFD) drugs for the treatment of infectious diseases in food animals (Allen and Stanton, 2014). Examples of these antibiotics include tilmicosin, florfenicol, avilamycin, apramycin, hygromycin and many more, which are to be used only for a specified time period depending on the animal species (Allen and Stanton, 2014). However, a recent in vitro study showed that certain zoonotic pathogens (Salmonella enterica, Listeria monocytogenes and Staphylococcus aureus) exposed to tilmicosin and florfenicol at a sub-inhibitory dosage exhibited acquired cross-resistance against several human antibiotics including ampicillin, tetracycline and nalidixic acid (Singh and Bhunia, 2019). This suggests that veterinary antimicrobials have the potential to induce cross-resistance in zoonotic pathogens thus would contribute to the increase in human antibiotic resistome.

Environment and wildlife: The environment has been considered a major source of antibiotic resistome (Ishii, 2019). Soil and aquatic environments are routinely exposed to animal and human waste. The residual antimicrobials (not metabolized) used in therapeutic or health-promoting applications can contaminate our environment through feces/urine. Water, soil, and wildlife including migratory birds can spread antibiotic resistance genes in the environment (Baquero et al., 2008; Allen et al., 2010; Bonnedahl and Järhult, 2014). Wastewater treatment plants are considered a hotspot for antibiotic resistance genes (Guo et al., 2017). Furthermore, improper disposal of antibiotics in the hospital and clinics can be a major environmental source of antibiotics (Wright, 2010). Veterinary antibiotics have been found in aquatic and terrestrial environments (Kemper, 2008). Management of antibiotic resistance in the environment would be a crucial strategy to reduce the spread of AMR (Berendonk et al., 2015).

Soil is a major source of antibiotic-resistant bacteria. Evidence suggests that the soil sample collected in the 1940s, showed an increased abundance of antibiotic-resistant genes (Knapp et al., 2009). The evidence further shows shared antibiotic resistance in 
soil bacteria and human pathogens (Forsberg et al., 2012). Manure applications in the agriculture field can also aid in the increased growth of antibiotic-resistant bacteria in the soil (Udikovic-Kolic et al., 2014).

Wildlife including migratory birds can spread antibiotic resistance genes very rapidly (Bonnedahl and Järhult, 2014). Reports indicate that wild birds are frequent carriers of ESBL producing E. coli (Alcalá et al., 2016; Sandegren et al., 2018). Farmed red deer and small mammals (Alonso et al., 2016), and reptiles in Galapagos islands (Wheeler et al., 2012), Brazilian grey-breasted parakeets (Machado et al., 2018), and Mallards (Sandegren et al., 2018) are reported to carry antibiotic-resistant enteric bacteria.

Stressors: Microbes are routinely exposed to various environmental or host induced stressors and they have developed strategies to overcome such adversity (Begley and Hill, 2015; Horn and Bhunia, 2018). It has been observed that bacterial exposure to various food preservation treatments including thermal or nonthermal including chemical processing treatments result in sub-lethal stress conditions which have been shown to increase antibiotic resistance in microbes (McMahon et al., 2007; Verraes et al., 2013; Horn and Bhunia, 2018). This is possibly achieved through the upregulation of global stress-response regulatory genes that are also involved in antimicrobial resistance (Poole, 2012; Singh et al., 2015). Stressors can also induce the expression of a multidrug efflux pump (Poole, 2012), and alter antimicrobial targets (Gunn, 2001) to overcome the adverse effects of antimicrobials (Tkachenko et al., 2012).

\section{Strategies to mitigate antimicrobial resistance}

The best practice would be to reduce indiscriminate use or misuse of antibiotics in animal health, human medicine and in agriculture (Wegener, 2003; Toutain et al., 2016). As mentioned above, banning of certain antibiotics in animal production can also lessen the abundance of antibiotic resistome. However, the question remains, if such a strategy alone would be sufficient to reduce the global antibiotic resistance problem. Credible alternative solutions are needed since antimicrobials are necessary for food animal production. Plant or animalderived antimicrobials, essential oils, enzymes, organic acids, prebiotics, and immunostimulants have been proposed as a substitute for antibiotics as growth promoters (Hashemi and Davoodi, 2011; Huyghebaert et al., 2011; Bhat et al., 2015). Development of new-generation drugs such as glycopeptide antibiotics that specifically target the cell wall biosynthesis is proposed (Sarkar et al., 2017). New-generation eco-friendly antimicrobials have been proposed that would have a limited effect on the commensals (gut microbial community) or the environment (Toutain et $a l ., 2016)$. In recent years, however, the use of microbes (bacteriophages, microflora, probiotics) as an eco-friendly tool to defend against antibiotic resistome (Kutateladze and Adamia, 2010; Jordan et al., 2014; Pamer, 2016; Wong and Santiago, 2017; Relman and Lipsitch, 2018) is gathering momentum for treatment of various diseases, as prophylactics or as growth promoters which are discussed below.

Bacteriophages: Bacteriophages are viruses that infect bacteria. They can multiply and cause lysis of the host bacterium (lytic phase) 
or can be maintained as prophage (lysogen). Their action is generally species-specific without affecting non-target bacteria including commensals. The first therapeutic application of bacteriophage in humans was reported in the early $20^{\text {th }}$ century (1921) by Felix d'Herelle to treat bacterial infection (cholera and bacillary dysentery) (Dublanchet and Bourne, 2007). In recent years, the resurgence of multidrug resistance in pathogens has found bacteriophage as a potential therapeutic agent to replace or supplement antibiotics (Merril et al., 1996; Gorski et al., 2009; Kutateladze and Adamia, 2010; Kortright et al., 2019). In 2006, USFDA approved bacteriophage as a biocontrol agent to prevent Listeria monocytogenes in cheese and since then multiple bacteriophage preparations have received GRAS (generally recognized as safe) status for controlling E. coli O157, Salmonella enterica, and Shigella spp. for food safety applications (Moye et al., 2018). To broaden bacteriophage activity against different species or strains of pathogens, bacteriophage cocktails are now used in food safety applications. There are several commercial phage products such as Salmonellex ${ }^{\mathrm{TM}}$, SalmoFresh ${ }^{\mathrm{TM}}$, EcoShield ${ }^{\circledR}$, PhageGuard ETM, Listex P-100 ${ }^{\mathrm{TM}}$, ListShield ${ }^{\circledR}$, and ShigaShield $®$ are available for control of zoonotic foodborne pathogens (Goodridge et al., 2018).

Bacteriophages have also found wide-spread application in livestock to reduce pathogen load in food animals (Cooper, 2016). The application of bacteriophages to control Salmonella and Campylobacter in poultry has been thoroughly reviewed (Grant et al., 2016). In the majority of application trials, bacteriophages were applied through the feed to chicks as well as slaughter age chickens that were artificially inoculated with pathogens. There was a significant reduction of these pathogens in finished birds (Carvalho et al., 2010; Bardina et al., 2012). The use of phage tail spike protein has been also shown to reduce Salmonella colonization in poultry (Waseh et al., 2010).

Bacteriophages have been also used to reduce Salmonella colonization in swine when applied through feed (Wall et al., 2010; Callaway et al., 2011; Zhang et al., 2015). Furthermore, direct feeding of a microencapsulated phage cocktail can also significantly reduce Salmonella shedding in pigs before slaughter (Saez et al., 2011). In a comprehensive six-week growth trial in pigs, researchers show that bacteriophages were able to suppress Salmonella counts, and promoted growth similar to growth-promoting antibiotics (Yan et al., 2012). Bacteriophages were also used in cattle to prevent $E$. coli O157:H7 colonization and shedding and were able to reduce bacterial load but failed to eliminate it completely (Sheng et al., 2006; Wang et al., 2017).

Endolysin, an enzyme produced by bacteriophage is responsible for bacterial cell lysis by hydrolyzing cell wall peptidoglycan therefore, purified endolysin has been considered a substitute for antibiotics (Borysowski et al., 2006). Recombinant endolysin also show similar potential therapeutic and prophylactic effects (Fenton et al., 2010).

Microbial community: It has been well accepted by the scientific community that exposure to the desirable microbial community early in life improves gut health, immune system development and infection 
resistance (Fuller, 1989; Marchesi et al., 2016; Marcolla et al., 2019). Promoting healthy microbial community in livestock through diet, probiotics, prebiotics, and husbandry practices can reduce pathogen load (Chambers and Gong, 2011; Stanley et al., 2014; Brugman et al., 2018). For example, increasing propionate producing commensal bacteria in the gut has been shown to exert colonization resistance against Salmonella infection (Jacobson et al., 2018). Animals through their natural feeding practices (such as coprophagy habit of birds) often receive fecal microbiota from their environment thus can help repopulate their diverse microbial community. However, such behavior can also allow pathogen ingestion from the environment as well.

Therefore, fecal microbiota transplantation from healthy (presumably free of zoonotic pathogens) in animals has been proposed for the control of certain diseases (Niederwerder, 2018). Direct-Fed Microbials (DFM) or Competitive Exclusion cultures (CE) have been used in poultry to reduce pathogen colonization and increased performance including meat and egg production. DFM may contain undefined cultures therefore, its use has been reduced significantly while CE containing known defined cultures are receiving greater acceptance (Callaway et al., 2017). In poultry production, hatchlings (day-old chick) fed with gut microflora have shown to reduce Campylobacter and Salmonella colonization thus reducing the use of antibiotics to control zoonotic pathogens (Tellez et al., 2012).

Fecal microbial implant from a healthy donor has proved to be an important therapeutic strategy for the treatment of diseases where antibiotic therapy is ineffective (Pamer, 2016). Such an approach would also reduce the use of antibiotics thus prevent the onset of acquired antibiotic resistance. Fecal microbiota has been shown to reduce antibiotic resistance genes in human patients suffering from recurrent Clostridium difficile infection (Millan et al., 2016). Furthermore, fecal microbiota transplants can also reduce intestinal colonization with antibiotic-resistant microbes (Crum-Cianflone et al., 2015; Woodworth et al., 2019). The major drawback of DFM is that the cultures are undefined, therefore, the microbial community may vary from batch to batch and may carry pathogens.

Probiotic bacteria: Probiotic bacteria consist of well-characterized defined cultures which exert health beneficial effects on the host (Amalaradjou and Bhunia, 2012; Hill et al., 2014; Plaza-Diaz et al., 2019). Among the probiotic bacteria, Lactobacillus, Bifidobacterium, Lactococcus, Pediococcus, Streptococcus, Enterococcus, Bacillus and yeast (Saccharomyces boulardi) are widely used. They survive, colonize, and modulate the immune system in the gut, and are considered safe (Lebeer et al., 2008; Amalaradjou and Bhunia, 2012; Ryan and Bhunia, 2017). Because of their competitive exclusion capacity and immunomodulatory function, these are considered an ideal substitute for antimicrobials in livestock diet (Cameron and McAllister, 2019). Therefore, the use of probiotics is one of the options being proposed by the scientific community as an alternative to antibiotics (Ouwehand et al., 2016; Hossain et al., 2017; Nair et al., 2018).

While it is relatively easier for a bacterial pathogen to develop resistance against 
antibiotics it is difficult to evolve against probiotics. This is largely due to the multiple inhibitory mechanisms employed by probiotics including the production of antimicrobial compounds (acids, bacteriocins), competitive exclusion and colonization resistance, immunomodulation and improved epithelial barrier function to prevent pathogen invasion (Pagnini et al., 2010; Amalaradjou and Bhunia, 2012; Bron et al., 2017; Ryan and Bhunia, 2017). Therefore, oral administration of certain competent probiotics may be a rationale and an effective alternative for preventing pathogen colonization in food animals, ameliorating disease and reducing antibiotic use (Gaggìa et al., 2010).

In livestock production, probiotics are commonly used for the competitive exclusion of pathogens such as Salmonella, Campylobacter, E. coli and Clostridium (Schneitz et al., 2016; Hofacre et al., 2019). Probiotics were also used in broilers to exclude ESBL E. coli (Ceccarelli et al., 2017), Salmonella (Tellez et al., 2012) and Campylobacter (Santini et al., 2010). Besides, probiotic application also improves feed intake, and weight performance in pigs (Yang et al., 2015; Pan et al., 2017; Wang et al., 2018), in beef and dairy cattle (Penha et al., 2011; Maldonado et al., 2018), in poultry (Rai et al., 2013; Callaway et al., 2017), in fish and shellfish (Kapareiko et al., 2011; LaraFlores, 2011; Ramos et al., 2013).

Among the probiotic bacteria, spore-forming Bacillus species have found widespread application in livestock production and in aquaculture as a growth promoter and is considered an ideal substitute for antibiotics (Guo et al., 2009; Nimrat et al., 2012;
Mingmongkolchai and Panbangred, 2018). Bacillus spp. has been used as DFM to promote growth, immunity and as an antibiotic substitute in poultry (Grant et al., 2018). The common probiotic Bacillus spp. include $B$. cereus B. clausii, B. pumilus, $B$. subtilis, B. coagulans and B. licheniformis (Cutting, 2011). Their ability to form spores allows them to survive well in feed/food and the gastric passage. The spores after passing through the stomach (acid acts as a stimulant) germinate and the vegetative cells can exert their probiotic action.

Bioengineered next-generation probiotics One of the limitations of probiotics is that the antimicrobial action may be species or strain specific. The probiotic action is largely dependent on their ability to stably colonize the gut. Adhesion to the mucosa or stable colonization and subsequent antiinflammatory and immunomodulatory actions are crucial for probiotic health benefits (Westermann et al., 2016; Yadav et al., 2017; Suez et al., 2019). Since not all probiotic possess such property, often, bioengineering approach has been employed to create nextgeneration organisms expressing desirable traits including adhesion molecules, cytokines (IL-10, IL-27), and enzymes (Amalaradjou and Bhunia, 2013; Sleator, 2015; Kumar et al., 2016; O'Toole et al., 2017). Such strains have shown increased ability to prevent pathogen colonization, exert immunomodulatory action and control infection. Lactobacillus casei strains expressing Listeria adhesion protein (LAP) was able to prevent L. monocytogenes interaction with the human intestinal epithelial cells in vitro and reduce Listeria induced cell damage (Koo et al., 2012; Drolia et al., 2018). Similarly, L. casei expressing invasion 
protein, InlAB was able to reduce $L$. monocytogenes colonization (Mathipa et al., 2019a; Mathipa et al., 2019b). Application of such bioengineered strains in food animals should be able to increase stable colonization of probiotic in the host, improve gut barrier function and reduce the spread of zoonotic pathogens and antibiotic resistome.

\section{Benefits of microbes as antimicrobials}

- Mechanism of antimicrobial action is multifaceted thus the development of acquired resistance is very low.

- Microbes may compete for the same niche as the pathogen in the host thus can exert colonization resistance.

- Bacteriophages are natural antimicrobials and can attack target pathogens effectively and has no known side effects on the host physiology.

- Some probiotic bacteria also produce organic acids (such as lactic acid, propionic acid, butyric acid, and acetic acid), bacteriocins, and hydrogen peroxide which are inhibitory towards pathogens.

- Probiotics have an immunomodulatory action and can improve gut barrier function, therefore, can prevent undesirable bacterial translocation across the gut epithelial barrier.

- Application of spore-forming probiotics (example, Bacillus spp.) would ensure increased survival in feed and the gastrointestinal tract.

- Bioengineering of a strain can enhance its colonization ability in the host or to help secrete antiinflammator or immunomodulatory cytokines.

\section{Limitations of microbes as antimicrobials}

- Reduced survival of microbes in the feed. The delivery strategy and extended survival of microbes in the feed should be ensured. Alternatively, spore-formers can increase survival in feed during storage.

- Some Bacillus spp. are known to produce toxins (enterotoxins) and antibiotics (ex. bacitracin, subtilin, etc), therefore, strains should be thoroughly screened before use.

- Mixed undefined culture (fecal implant or microflora) may carry pathogens or microbes carrying antibiotic resistance genes which may become an unintentional source of AMR.

- Antimicrobial action of bacteriophage depends on the presence of the target pathogen. In the absence of the target host, bacteriophage may disappear from the host.

- Bacteriophages may carry antibiotic marker genes or other virulence genes thus they should be thoroughly screened before application.

- The development of resistance to bacteriophages could be a problem.

- Bacteriophage production requires the growth of large volumes of host pathogens which can be hazardous 
during mass production and the chance of contamination of bacteriophage preparation with the host bacterial pathogens.

- Probiotic LAB should be thoroughly characterized before application but the major limitation is its ability to stably colonize the host gut. Probiotic from a heterologous source may not colonize a host thus they may be excluded from the body without colonization and may have limited antimicrobial activity.

- Bioengineered probiotic strains can have increased colonization depending on the type of genes being introduced, however, the strain should be made in such a way that they do not survive outside the host so environmental spread can be minimized.

Indiscriminate use or misuse of antibiotics coupled with a lack of investment in developing new drugs culminated in the global antibiotic resistance crisis today. It is nearly impossible to entirely eliminate antibiotic resistance in microbes, but the clinical or animal husbandry practices that can reduce further development of acquired resistance to antibiotics should be explored. One caveat, any credible solution to reduce antibiotic resistance in bacteria should be able to withstand the resistant mechanisms used by bacteria in the first place.

Antibiotics resistome are widespread and are routinely isolated from food animals, wildlife, foods, soil, water and the environment. Modern intensified animal agriculture practice has been identified as the major contributing factor and the banning of certain antibiotics has shown a positive result and reduced antibiotic resistome in foods and in humans. However, antimicrobials use in food animal production, poultry industry and in aquaculture are essential to treat and prevent the spread of diseases. Furthermore, agriculture scientists are continuously being reminded of growing human populations on the planet and the demand for increased food production in the next few decades. Therefore, any changes in our husbandry practices that can potentially affect food (milk, egg, meat) yield and the profit margins for the farmers would face resistance.

Alternative but equally effective as antibiotic must be developed that can replace antibiotic use in food animal production and environmental burden without affecting the animal health or growth performance. Therefore, in recent years, eco-friendly new generation antimicrobials including microbes such as bacteriophages, mixed microflora, probiotic bacteria, bioengineered microbes, microbial by-products, and plant or animal-derived antimicrobials are investigated as a potential antibiotic replacement or as an antibiotic supplement.

Besides promoting antibiotic stewardship, the total banning of antibiotics especially the "medically relevant" antibiotics for growth promotion should be enforced. At the same time, each country should make a commitment to invest funds towards research and development to produce eco-friendly antimicrobials including vaccines that are well suited for their husbandry practices for the animal, poultry, and fish production. 


\section{ACKNOWLEDGMENTS}

The research in the author's laboratory is funded by the U.S. Department of Agriculture, Agricultural Research Service (59-8072-6001), the USDA National Institute of Food and Agriculture (Hatch accession no. 1016249), the National Academy of Science (NAS) and US-AID Award No. AID-263-A-

\section{REFERENCES}

Alcalá L, Alonso CA, Simón C, González-Esteban C, Orós J et al., 2016. Wild birds, frequent carriers of extended-spectrum $\beta$-lactamase (ESBL) producing Escherichia coli of CTX-M and SHV-12 types. Microb Ecol, 72: 861-869

Allen HK, Donato J, Wang HH, Cloud-Hansen KA, Davies J et al., 2010. Call of the wild: antibiotic resistance genes in natural environments. Nat Rev Microbiol, 8: 251

Allen HK and Stanton TB, 2014. Altered egos: Antibiotic effects on food animal microbiomes. Annu Rev Microbiol, 68: 297-315

Alonso CA, González-Barrio D, Tenorio C, RuizFons F and Torres C, 2016. Antimicrobial resistance in faecal Escherichia coli isolates from farmed red deer and wild small mammals. Detection of a multiresistant E. coli producing extended-spectrum beta-lactamase. Comp Immunol Microbiol Infect Dis, 45: 34-39

Amalaradjou MAR and Bhunia AK, 2012. Modern approaches in probiotics research to control foodborne pathogens. Adv Food Nutr Res, 67: 185-239

Amalaradjou MAR and Bhunia AK, 2013. Bioengineered probiotics, a strategic approach to control enteric infections. Bioengineered, 4: 291-299

Andersson DI and Hughes D, 2014. Microbiological effects of sublethal levels of antibiotics. Nat Rev Microbiol, 12: 465-478
15-00002, BioMatrix International, and the Center for Food Safety Engineering at Purdue University. Any opinions, findings, conclusions, or recommendations expressed in this publication are those of the author and do not necessarily reflect the view of the USDA, USAID or NAS. The author declares no competing interest.

Bager F, Madsen M, Christensen J and Aarestrup FM, 1997. Avoparcin used as a growth promoter is associated with the occurrence of vancomycin-resistant Enterococcus faecium on Danish poultry and pig farms. Prev Vet Med, 31: 95-112

Baquero F, Martínez JL and Cantón R, 2008. Antibiotics and antibiotic resistance in water environments. Curr Opin Biotechnol, 19: 260265

Bardina C, Spricigo DA, Cortés P and Llagostera M, 2012. Significance of the bacteriophage treatment schedule in reducing Salmonella colonization of poultry. Appl Environ Microbiol, 78: 6600-6607

Beceiro A, Tomas M and Bou G, 2013. Antimicrobial resistance and virulence: a successful or deleterious association in the bacterial world? Clin Microbiol Rev, 26: 185-230

Begley M and Hill C, 2015. Stress adaptation in foodborne pathogens. Annu Rev Food Sci Technol, 6: 191-210

Bengtsson-Palme J and Larsson DJ, 2016. Concentrations of antibiotics predicted to select for resistant bacteria: Proposed limits for environmental regulation. Environ Int, 86: 140-149

Berendonk TU, Manaia CM, Merlin C, FattaKassinos D, Cytryn E et al., 2015. Tackling antibiotic resistance: the environmental framework. Nat Rev Microbiol, 13: 310 
Bhat ZF, Kumar S and Bhat HF, 2015. Bioactive peptides of animal origin: a review. J Food Sci Technol, 52: 5377-5392

Blair JMA, Richmond GE and Piddock LJV, 2014. Multidrug efflux pumps in gram-negative bacteria and their role in antibiotic resistance. Future Microbiol, 9: 1165-1177

Bonnedahl J and Järhult JD, 2014. Antibiotic resistance in wild birds. Upsala J Med Sci, 119: 113-116

Borysowski J, Weber-Dạbrowska B and Górski A, 2006. Bacteriophage endolysins as a novel class of antibacterial agents. Exp Biol Med, 231: $366-377$

Bron PA, Kleerebezem M, Brummer R-J, Cani PD, Mercenier A et al., 2017. Can probiotics modulate human disease by impacting intestinal barrier function? Brit J Nutr, 117: 93-107

Brugman S, Ikeda-Ohtsubo W, Braber S, Folkerts G, Pieterse CMJ et al., 2018. A comparative review on microbiota manipulation: lessons from fish, plants, livestock and human research. Front Nutr, 5: 80

Brüssow H, 2017. Adjuncts and alternatives in the time of antibiotic resistance and in-feed antibiotic bans. Microb Biotechnol, 10: 674677

Callaway TR, Edrington TS, Brabban A, Kutter B, Karriker L et al., 2011. Evaluation of phage treatment as a strategy to reduce Salmonella populations in growing swine. Foodborne Pathog Dis, 8: 261-266

Callaway TR, Edrington TS, Byrd JA, Nisbet DJ and Ricke SC, 2017. Chapter 15 - Use of Direct-Fed Microbials in Layer Hen Production-Performance Response and Salmonella Control". In Producing Safe Eggs eds. Ricke SC and Gast RK. pp301-322. San Diego: Academic Press

Cameron A and McAllister TA, 2019. Could probiotics be the panacea alternative to the use of antimicrobials in livestock diets? Beneficial Microbes, 1-28 (Published online on August 27, 2019)

Carlet J, Jarlier V, Harbarth S, Voss A, Goossens H et al., 2012. Ready for a world without antibiotics? The pensieres antibiotic resistance call to action. Antimicrob Resist Infect Control, 1: 1-11

Carvalho CM, Gannon BW, Halfhide DE, Santos SB, Hayes CM et al., 2010. The in vivo efficacy of two administration routes of a phage cocktail to reduce numbers of Campylobacter coli and Campylobacter jejuni in chickens. BMC Microbiol, 10: 232

Cassini A, Högberg LD, Plachouras D, Quattrocchi A, Hoxha A et al., 2019. Attributable deaths and disability-adjusted life-years caused by infections with antibiotic-resistant bacteria in the EU and the European Economic Area in 2015: a population-level modelling analysis. Lancet Infect Dis, 19: 56-66

CDC, 2018. Antibiotic Resistance: A Global Threat. https://www.cdc.gov/features/antibioticresistance-global/index.html: Accessed on August 30, 2019

Ceccarelli D, van Essen-Zandbergen A, Smid B, Veldman KT, Boender GJ et al., 2017. Competitive exclusion reduces transmission and excretion of extended-spectrum- $\beta$ lactamase-producing Escherichia coli in broilers. Appl Environ Microbiol, 83: e0343903416

Chambers JR and Gong J, 2011. The intestinal microbiota and its modulation for Salmonella control in chickens. Food Res Int, 44: 31493159 
Cheng G, Hao H, Xie S, Wang X, Dai M et al., 2014. Antibiotic alternatives: The substitution of antibiotics in animal husbandry? Front Microbiol, 5: 217

Cooper IR, 2016. A review of current methods using bacteriophages in live animals, food and animal products intended for human consumption. $\mathbf{J}$ Microbiol Methods, 130: 38-47

Crum-Cianflone NF, Sullivan E and Ballon-Landa $\mathrm{G}, 2015$. Fecal microbiota transplantation and successful resolution of multidrug-resistantorganism colonization. J Clin Microbiol, 53: 1986-1989

Cutting SM, 2011. Bacillus probiotics. Food Microbiol, 28: 214-220

D'Costa VM, King CE, Kalan L, Morar M, Sung WWL et al., 2011. Antibiotic resistance is ancient. Nature, 477: 457-461

Davies J and Davies D, 2010. Origins and evolution of antibiotic resistance. Microbiol Mol Biol Rev, 74: 417-433

de Kraker MEA, Stewardson AJ and Harbarth S, 2016. Will 10 million people die a year due to antimicrobial resistance by 2050 ? PLoS Med, 13: e1002184

Drolia R, Tenguria S, Durkes AC, Turner JR and Bhunia AK, 2018. Listeria adhesion protein induces intestinal epithelial barrier dysfunction for bacterial translocation. Cell Host Microbe, 23: 470-484

Dublanchet A and Bourne S, 2007. The epic of phage therapy. Can J Infect Dis Med Microbiol, 18: 15-18

Fenton M, McAuliffe O, O’Mahony J and Coffey A, 2010. Recombinant bacteriophage lysins as antibacterials. Bioengineered Bugs, 1: 9-16

Ferri M, Ranucci E, Romagnoli P and Giaccone V, 2017. Antimicrobial resistance: a global emerging threat to public health systems. Crit Rev Food Sci Nutr, 57: 2857-2876

Forsberg KJ, Reyes A, Wang B, Selleck EM, Sommer MOA et al., 2012. The shared antibiotic resistome of soil bacteria and human pathogens. Science, 337: 1107-1111

Fuller R, 1989. Probiotics in man and animals. J Appl Bacteriol, 66: 365-378

Gaggìa F, Mattarelli P and Biavati B, 2010. Probiotics and prebiotics in animal feeding for safe food production. Int J Food Microbiol, 141: S15-S28

Goodridge L, Fong K, Wang S and Delaquis P, 2018. Bacteriophage-based weapons for the war against foodborne pathogens. Curr Opin Food Sci, 20: 69-75

Gorski A, Miedzybrodzki R, Borysowski J, WeberDabrowska B, Lobocka M et al., 2009. Bacteriophage therapy for the treatment of infections. Curr Opin Invest Drugs, 10: 766-774

Grant AQ, Gay CG and Lillehoj HS, 2018. Bacillus spp. as direct-fed microbial antibiotic alternatives to enhance growth, immunity, and gut health in poultry. Avian Pathol, 47: 339351

Grant AQ, Hashem F and Parveen S, 2016. Salmonella and Campylobacter: Antimicrobial resistance and bacteriophage control in poultry. Food Microbiol, 53: 104-109

Gullberg E, Cao S, Berg OG, Ilback C, Sandegren L et al., 2011. Selection of resistant bacteria at very low antibiotic concentrations. PLoS Pathog, 7(7): e1002158

Gunn JS, 2001. Bacterial modification of LPS and resistance to antimicrobial peptides. J Endotox Res, 7: 57-62

Guo J, Li J, Chen H, Bond PL and Yuan Z, 2017. Metagenomic analysis reveals wastewater 
treatment plants as hotspots of antibiotic resistance genes and mobile genetic elements. Water Res, 123: 468-478

Guo JJ, Liu KF, Cheng SH, Chang CI, Lay JJ et al., 2009. Selection of probiotic bacteria for use in shrimp larviculture. Aquaculture Res, 40: 609-618

Hashemi SR and Davoodi H, 2011. Herbal plants and their derivatives as growth and health promoters in animal nutrition. Vet Res Comm, 35: $169-180$

Hill C, Guarner F, Reid G, Gibson GR, Merenstein DJ et al., 2014. Expert consensus document: The International Scientific Association for Probiotics and Prebiotics consensus statement on the scope and appropriate use of the term probiotic. Nat Rev Gastroenterol Hepatol, 11: 506-514

Hofacre CL, Reynolds DJ, Mathis GF, Lumpkins BS, Ollis Net al., 2019. Effect of a competitive exclusion culture in a necrotic enteritis challenge model in broilers. J Appl Poultry Res, 28: 350-355

Horn N and Bhunia AK, 2018. Food-associated stress primes foodborne pathogens for the gastrointestinal phase of infection. Front Microbiol, 9: 1962

Hossain MI, Sadekuzzaman M and Ha SD, 2017. Probiotics as potential alternative biocontrol agents in the agriculture and food industries: A review. Food Res Int, 100: 63-73

Huyghebaert G, Ducatelle R and Immerseel FV, 2011. An update on alternatives to antimicrobial growth promoters for broilers. Vet J, 187: 182-188

Ishii S, 2019. Ecology of pathogens and antibioticresistant bacteria in environments: Challenges and opportunities. Microbes Environ, 34: 1-4
Jacobson A, Lam L, Rajendram M, Tamburini F, Honeycutt $\mathrm{J}$ et al., 2018. A gut commensalproduced metabolite mediates colonization resistance to Salmonella infection. Cell Host Microbe, 24: 296-307

Jordan K, Dalmasso M, Zentek J, Mader A, Bruggeman G et al., 2014. Microbes versus microbes: Control of pathogens in the food chain. J Sci Food Agri, 94: 3079-3089

Kapareiko D, Lim HJ, Schott EJ, Hanif A and Wikfors GH, 2011. Isolation and evaluation of new probiotic bacteria for use in shellfish hatcheries: II. Effects of a Vibrio sp. probiotic candidate upon survival of oyster larvae (Crassostrea virginica) in pilot-scale trials. J Shellfish Res, 30: 617-626

Kemper N, 2008. Veterinary antibiotics in the aquatic and terrestrial environment. Ecol Indicators, 8: 1-13

Knapp CW, Dolfing J, Ehlert PAI and Graham DW, 2009. Evidence of increasing antibiotic resistance gene abundances in archived soils since 1940. Environ Sci Technol, 44: 580587

Koo OK, Amalaradjou MAR and Bhunia AK, 2012. Recombinant probiotic expressing Listeria adhesion protein attenuates Listeria monocytogenes virulence in vitro. PLoS One, 7: e29277

Kortright KE, Chan BK, Koff JL and Turner PE, 2019. Phage therapy: A renewed approach to combat antibiotic-resistant bacteria. Cell Host Microbe, 25(2): 219-232

Kumar M, Yadav AK, Verma V, Singh B, Mal G et al., 2016. Bioengineered probiotics as a new hope for health and diseases: An overview of potential and prospects. Future Microbiol, 11: 585-600 
Kutateladze M and Adamia R, 2010. Bacteriophages as potential new therapeutics to replace or supplement antibiotics. Trends Biotechnol, 28: 591-595

Lara-Flores M, 2011. The use of probiotic in aquaculture: An overview. Int Res J Microbiol, 2: 471-478

Lebeer S, Vanderleyden J and De Keersmaecker SCJ, 2008. Genes and molecules of Lactobacilli supporting probiotic action. Microbiol Mol Biol Rev, 72: 728-764

Machado DN, Lopes ES, Albuquerque AH, Horn RV, Bezerra WGA et al., 2018. Isolation and antimicrobial resistance profiles of enterobacteria from Nestling Grey-Breasted Parakeets (Pyrrhura Griseipectus). Brazilian J Poultry Sci, 20: 103-110

Maldonado NC, Ficoseco CA, Mansilla FI, Melián C, Hébert EM et al., 2018. Identification, characterization and selection of autochthonous lactic acid bacteria as probiotic for feedlot cattle. Livestock Sci, 212: 99-110

Marchesi JR, Adams DH, Fava F, Hermes GDA, Hirschfield GM et al., 2016. The gut microbiota and host health: A new clinical frontier. Gut, 65: 330-339

Marcolla CS, Alvarado CS and Willing B, 2019. Early life microbial exposure shapes subsequent animal health. Can J Anim Sci, (published onlin July 15, 2019) https:// doi.org/10.1139/cjas-2019-0029:

Marshall BM and Levy SB, 2011. Food animals and antimicrobials: Impacts on human health. Clin Microbiol Rev, 24: 718-733

Mathew AG, Cissell R and Liamthong S, 2007. Antibiotic resistance in bacteria associated with food animals: A United States perspective of livestock production. Foodborne Pathog Dis, 4: 115-133

Mathipa MG, Bhunia AK and Thantsha MS, 2019a. Internalin AB-expressing recombinant Lactobacillus casei protects Caco- 2 cells from Listeria monocytogenes-induced damages under simulated intestinal conditions. PLoS One, 14: e0220321

Mathipa MG, Thantsha MS and Bhunia AK, 2019b. Lactobacillus casei expressing Internalins $\mathrm{A}$ and $\mathrm{B}$ reduces Listeria monocytogenes interaction with Caco- 2 cells in vitro. Microb Biotechnol, 12: 715-729

McMahon MAS, Xu J, Moore JE, Blair IS and McDowell DA, 2007. Environmental stress and antibiotic resistance in food-related pathogens. Appl Environ Microbiol, 73: 211-217

Merril CR, Biswas B, Carlton R, Jensen NC, Creed GJ et al., 1996. Long-circulating bacteriophage as antibacterial agents. Proc Nat Acad Sci USA, 93: 3188-3192

Millan B, Park H, Hotte N, Mathieu O, Burguiere P et al., 2016. Fecal microbial transplants reduce antibiotic-resistant genes in patients with recurrent Clostridium difficile infection. Clin Infec Dis, 62: 1479-1486

Mingmongkolchai S and Panbangred W, 2018. Bacillus probiotics: an alternative to antibiotics for livestock production. J Appl Microbiol, 124: 1334-1346

Moye ZD, Woolston J and Sulakvelidze A, 2018. Bacteriophage applications for food production and processing. Viruses, 10: 205

Nair D, Venkitanarayanan K and Kollanoor Johny A, 2018. Antibiotic-resistant Salmonella in the food supply and the potential role of antibiotic alternatives for control. Foods, 7: 167 
Neu HC, 1992. The crisis in antibiotic resistance. Science, 257: 1064-1073

Niederwerder MC, 2018. Fecal microbiota transplantation as a tool to treat and reduce susceptibility to disease in animals. Vet Immunol Immunopathol, 206: 65-72

Nimrat $S$, Suksawat $S$, Boonthai $T$ and Vuthiphandchai V, 2012. Potential Bacillus probiotics enhance bacterial numbers, water quality and growth during early development of white shrimp (Litopenaeus vannamei). Vet Microbiol, 159: 443-450

O’Neill J, 2014. Antimicrobial resistance: tackling a crisis for the health and wealth of nations. Rev Antimicrob Resist, 1-16

O'Toole PW, Marchesi JR and Hill C, 2017. Nextgeneration probiotics: The spectrum from probiotics to live biotherapeutics. Nat Microbiol, 2: 17057

Ouwehand AC, Forssten S, Hibberd AA, Lyra A and Stahl B, 2016. Probiotic approach to prevent antibiotic resistance. Annals Med, 48: 246-255

Pagnini C, Saeed R, Bamias G, Arseneau KO, Pizarro TT et al., 2010. Probiotics promote gut health through stimulation of epithelial innate immunity. Proc Natl Acad Sci U S A, 107: 454-459

Pamer EG, 2016. Resurrecting the intestinal microbiota to combat antibiotic-resistant pathogens. Science, 352: 535-538

Pan L, Zhao PF, Ma XK, Shang QH, Xu YT et al., 2017. Probiotic supplementation protects weaned pigs against enterotoxigenic Escherichia coli K88 challenge and improves performance similar to antibiotics. J Anim Sci, 95: 2627-2639

Penha LAC, Pardo PE, Kronka SN, Reis L, Oba E et al., 2011. Effects of probiotic supplementation on liveweight gain and serum cortisol concentration in cattle. Vet Record, 168: 538538

Pérez-Rodríguez F and Mercanoglu Taban B, 2019. A state-of-art review on multi-drug resistant pathogens in foods of animal origin: risk factors and mitigation strategies. Front Microbiol, 10: 2091

Plaza-Diaz J, Ruiz-Ojeda FJ, Gil-Campos M and Gil A, 2019. Mechanisms of action of probiotics. Adv Nutr, 10: S49-S66

Poole K, 2012. Bacterial stress responses as determinants of antimicrobial resistance. J Antimicrob Chemother, 67: 2069-2089

Rai V, Yadav B and Lakhani GP, 2013. Application of probiotic and prebiotic in animals production: A review. Envion Ecol, 31: 873876

Ramos MA, Weber B, Gonçalves JF, Santos GA, Rema P et al., 2013. Dietary probiotic supplementation modulated gut microbiota and improved growth of juvenile rainbow trout (Oncorhynchus mykiss). Comp Biochem Physiol Prt A: Mol Integrative Physiol, 166: 302-307

Relman DA and Lipsitch M, 2018. Microbiome as a tool and a target in the effort to address antimicrobial resistance. Proc Nat Acad Sci U S A, 115: 12902

Rodriguez-Rojas A, Rodriguez-Beltran J, Couce A and Blazquez J, 2013. Antibiotics and antibiotic resistance: a bitter fight against evolution. Int J Med Microbiol, 303: 293-297

Ryan V and Bhunia AK, 2017. Mitigation of Foodborne Illnesses by Probiotics. In Foodborne Pathogens; Virulence Factors and Host Susceptibility. pp603-634: Springer-Nature 
Saez AC, Zhang J, Rostagno MH and Ebner PD, 2011. Direct feeding of microencapsulated bacteriophages to reduce Salmonella colonization in pigs. Foodborne Pathog Dis, 8: $1269-1274$

Sandegren L, Stedt J, Lustig U, Bonnedahl J, Andersson DI et al., 2018. Long term carriage and rapid transmission of extended spectrum beta lactamase producing E. coli within a flock of Mallards in the absence of antibiotic selection. Environ Microbiol Reports, 10: 576-582

Santini C, Baffoni L, Gaggia F, Granata M, Gasbarri $\mathrm{R}$ et al., 2010. Characterization of probiotic strains: An application as feed additives in poultry against Campylobacter jejuni. Int $\mathbf{J}$ Food Microbiol, 141: S98-S108

Sarkar P, Yarlagadda V, Ghosh C and Haldar J, 2017. A review on cell wall synthesis inhibitors with an emphasis on glycopeptide antibiotics. Medchemcomm, 8: 516-533

Schneitz C, Koivunen E, Tuunainen P and Valaja J, 2016. The effects of a competitive exclusion product and two probiotics on Salmonella colonization and nutrient digestibility in broiler chickens. J Appl Poultry Res, 25: 396406

Sheng H, Knecht HJ, Kudva IT and Hovde CJ, 2006. Application of bacteriophages to control intestinal Escherichia coli O157: H7 levels in ruminants. Appl Environ Microbiol, 72: $5359-5366$

Singh AK and Bhunia AK, 2019. Animal-use antibiotics induce cross-resistance in bacterial pathogens to human therapeutic antibiotics. Curr Microbiol, 76: 1112-1117

Singh AK, Drolia R, Bai X and Bhunia AK, 2015. Streptomycin induced stress response in Salmonella enterica serovar Typhimurium shows distinct colony scatter signature. PLoS One, 10: e0135035
Sleator RD, 2015. Designer probiotics: Development and applications in gastrointestinal health. World J Gastrointest Pathophysiol, 6: 73-78

Stanley D, Hughes RJ and Moore RJ, 2014. Microbiota of the chicken gastrointestinal tract: influence on health, productivity and disease. Appl Microbiol Biotechnol, 98: 4301-4310

Suez J, Zmora N, Segal E and Elinav E, 2019. The pros, cons, and many unknowns of probiotics. Nat Med, 25: 716-729

Tellez G, Pixley C, Wolfenden RE, Layton SL and Hargis BM, 2012. Probiotics/direct fed microbials for Salmonella control in poultry. Food Res Int, 45: 628-633

Tkachenko AG, Akhova AV, Shumkov MS and Nesterova LY, 2012. Polyamines reduce oxidative stress in Escherichia coli cells exposed to bactericidal antibiotics. Res Microbiol, 163: 83-91

Toutain PL, Ferran AA, Bousquet-Melou A, Pelligand L and Lees P, 2016. Veterinary medicine needs new green antimicrobial drugs. Front Microbiol, 7: 1196

Udikovic-Kolic N, Wichmann F, Broderick NA and Handelsman J, 2014. Bloom of resident antibiotic-resistant bacteria in soil following manure fertilization. Proc Nat Acad Sci USA, 111: 15202-15207

Van Boeckel TP, Brower C, Gilbert M, Grenfell BT, Levin SA et al., 2015. Global trends in antimicrobial use in food animals. Proc Nat Acad Sci USA, 112: 5649-5654

Verraes C, Van Boxstael S, Van Meervenne E, Van Coillie E, Butaye P et al., 2013. Antimicrobial resistance in the food chain: A review. Int $\mathrm{J}$ Environ Res Pub Health, 10: 2643-2669

Wall SK, Zhang J, Rostagno MH and Ebner PD, 
2010. Phage therapy to reduce preprocessing Salmonella infections in market-weight swine. Appl Environ Microbiol, 76: 48-53

Wang J, Zeng Y, Wang S, Liu H, Zhang D et al., 2018. Swine-derived probiotic Lactobacillus plantarum inhibits growth and adhesion of enterotoxigenic Escherichia coli and mediates host defense. Front Microbiol, 9: 1364

Wang L, Qu K, Li X, Cao Z, Wang X et al., 2017. Use of bacteriophages to control Escherichia coli O157: $\mathrm{H} 7$ in domestic ruminants, meat products, and fruits and vegetables. Foodborne Pathog Dis, 14: 483-493

Waseh S, Hanifi-Moghaddam P, Coleman R, Masotti M, Ryan S et al., 2010. Orally administered P22 phage tailspike protein reduces Salmonella colonization in chickens: prospects of a novel therapy against bacterial infections. PLoS One, 5: e13904

Wegener HC, 2003. Antibiotics in animal feed and their role in resistance development. Curr Opin Microbiol, 6: 439-445

Westermann C, Gleinser M, Corr SC and Riedel CU, 2016. A Critical Evaluation of Bifidobacterial Adhesion to the Host Tissue. Front Microbiol, 7: 1220

Wheeler E, Hong PY, Bedon LC and Mackie RI, 2012. Carriage of antibiotic-resistant enteric bacteria varies among sites in Galapagos reptiles. J Wildlife Dis, 48: 56-67

Wong WF and Santiago M, 2017. Microbial approaches for targeting antibiotic-resistant bacteria. Microb Biotechnol, 10: 1047-1053
Woodworth MH, Hayden MK, Young VB and Kwon JH, 2019. The Role of Fecal microbiota transplantation in reducing intestinal colonization with antibiotic-resistant organisms: The Current landscape and future directions. Open Forum Infect Dis, 6(7): ofz288. doi: 10.1093/ofid/ofz288

Wright GD, 2010. Antibiotic resistance in the environment: a link to the clinic? Curr Opin Microbiol, 13: 589-594

Yadav AK, Tyagi A, Kumar A, Panwar S, Grover S et al., 2017. Adhesion of Lactobacilli and their anti-infectivity potential. Crit Rev Food Sci Nutr, 57: 2042-2056

Yan L, Hong SM and Kim IH, 2012. Effect of bacteriophage supplementation on the growth performance, nutrient digestibility, blood characteristics, and fecal microbial shedding in growing pigs. Asian-Australasian J Anim Sci, 25: 1451

Yang F, Hou C, Zeng X and Qiao S, 2015. The use of lactic acid bacteria as a probiotic in swine diets. Pathogens, 4: 34-45

Zhang J, Li Z, Cao Z, Wang L, Li X et al., 2015. Bacteriophages as antimicrobial agents against major pathogens in swine: A review. J Anim Sci Biotechnol, 6: 39

Zhu X, Liu D, Singh AK, Drolia R, Bai X et al., 2018. Tunicamycin mediated inhibition of wall teichoic acid affect Staphylococcus aureus and Listeria monocytogenes cell morphology, biofilm formation and virulence. Front Microbiol, 9: 1352

Article received on 03.10.2019 and accepted for publication on 22.10.2019 